\title{
Impact of coordination training on the development of speed among young judokas from 10 to 12 years old
}

\author{
Zeghari L. ${ }^{\mathrm{ABCD}}$, Moufti H. ${ }^{\mathrm{ABCD}}$, Arfaoui A. ${ }^{\mathrm{CD}}$, Gaidi.A. ${ }^{\mathrm{AB}}$, Addal K. ${ }^{\mathrm{AB}}$ \\ Royal Institute of Management training, National Center of Sports Moulay Rachid, Salé, Morocco
}

Authors' Contribution: A - Study design; B - Data collection; C - Statistical analysis; D - Manuscript Preparation; E - Funds Collection.

\begin{abstract}
Purpose:

Judo is a combat sport requiring physical qualities that include speed and coordination. They are essential for brief and intense attacks. Study the impact of a training based on coordination adapted to the age group (10 to 12 years) on the development of speediness among young's judokas.

Material: $\quad$ The study was conducted at Svelty Club, sports association in Kenitra, city in north-western Morocco, from March $2^{\text {nd }}, 2019$ to May $5^{\text {th }}, 2019$, on a sample of 12 young judoka aged from 10 to 12 years divided into two groups, control group and experimental group. At first both groups received two tests, $10 \mathrm{~m}$ speed test and Uchi Komi test, which we considered initial tests. The experimental group had a training program spread over 12 weeks that focused on the development of speed through coordination. For the control group, we followed the regular training of the club. Both tests were re-administered after the end of the training program (final tests).

Results: $\quad$ The initial test value for the experimental group for Uchi Komi test was $7 \pm 0.9$, and the final test was $8.7 \pm 1.03$, which shows a significant difference according to the $T$ test, $(p=0.001 \leq 0.05)$ in contrast to the control group $(p=0.23 \geq 0.05)$. For the $10 \mathrm{~m}$ speed test, the experimental group showed a significant difference between the value of the initial test and the final test $(p=0.003 \leq 0.05)$, unlike the control group $(p=0.93 \geq 0.05)$.

Conclusions: $\quad$ The development of physical qualities is still the primary goal of coaches; however this development is more decisive for young athletes. Our study has shown that a coordination training adapted to each athlete's age can help coaches better develop other qualities namely speed.

Keywords: training, young, speed, coordination, judo, athlete.
\end{abstract}

\section{Introduction}

Judo is a highly demanding fighting sport. It requires the development of speediness for brief and intense maneuvers alongside endurance through the repetition of attacks. Furthermore, it prizes the mastery of coordination for an efficient execution of movements. A judo battle is composed of a succession of intermittent, brief and intense efforts, lasting a total of seven to eight minutes and inducing a strong demand of the different energy sectors [1-3].

A perfect physical condition is necessary for an optimal expression of the techniques that define the success of a judoka [4, 5]. For judo practitioners under 12 years of age the situation is a little more intricate. If the charge is univocal, early hyper-specific training can be problematic promoting muscle imbalances that could subsequently alter these young Judokas' development. Many children would not develop their maximum sport potential simply because the stimuli applied during their growth were insufficient or unambiguous. [6-8].

Hypothesis: Specific coordination training will have an impact on the development of speed among an age group of judokas from 10 to 12 years old.

Purpose: Study the impact of a training based on coordination adapted to the age group (10 to 12 years) focusing on the development of speediness among these young judokas through two tests, a speed test on $10 \mathrm{~m}$ and a specific test Uchi Komi; a fundamental exercise in the physical and technical preparation of judoka [9].

(c) Zeghari L., Moufti H., Arfaoui A., Gaidi.A., Addal K., 2019 doi:10.15561/18189172.2019.0608

\section{Material and methods}

Participants:

The present study was conducted at Svelty Club, sports association founded on October 13, 2013 in Kenitra, city in north-western Morocco, which contains over 80 licensees. The study was conducted from March $3^{\text {rd }}, 2019$ to May $4^{\text {th }}, 2019$, all Tuesday, Thursday and Saturday from 7 PM to 8 PM.

The population is made up of 12 male judokas from the club ASSOCIATION SVELTY CLUB. These subjects were chosen in a random way, forming two groups:

- An experimental group whose age was between 10 and 12 years, with a mean age of $11.33 \pm 1.03$, and a weight between 41 and $78 \mathrm{~kg}$ and a mean of $53.33 \pm$ 14.65 .

- A control group whose age was between 10 and 12 years, with a mean age of $11.33 \pm 1.03$, and a weight between 40 and $55 \mathrm{~kg}$, and a mean of $46.16 \pm 5.78$.

Research Design:

Before applying the tests, both experimental and control groups perform specific warm-up exercises to avoid injury and prepare the muscle for exertion by increasing body temperature.

Step 1: Applying the initial tests to assess the initial level of each member of both groups (experimental and control).

\section{Test 1: Speed test on 10m:}

- The subject must be behind the starting line, the stopwatch is triggered when the subject's rear foot leaves the ground, and stops when he crosses the finish line, the subject must perform 3 tries and the best time is recorded 
[10], the objective of this test is to evaluate the ability to start explosively.

\section{Test 2: Uchi komi:}

- The subject must perform the maximum number of repetitions on ippon-seoi-nage for 10 seconds, he must keep the rhythm adopted from the outset and especially the gestural quality at the time of execution of the technical gesture [11], however the test procedure must comply with the following conditions:

- Rotate completely and return from the front,

- Both feet on the same line,

- The hand back on the reverse.

Step 2: Development of an adapted training program focused on speed development through coordination (see Appendix):

After initial testing, we set up a specific training plan to develop speed among young judokas aged 10 to 12 years, while taking into consideration the fundamental principles of progression (from simple to complex), respect the stages of development, the load of the exercises and the principle effort-recovery.

The training program was spread over a period of 12 weeks, with three training sessions per week, making a total of 36 sessions lasting 60 minutes each.

Step 3: repeat the tests $(10 \mathrm{~m}$ speed test and Uchi Komi test) under the same conditions of the initial tests that we will consider final tests.
Statistical analysis:

For the analysis of the evolution between the two groups we chose $\mathrm{T}$ test of the paired samples, with the software SPSS version 25.

\section{Results}

\section{Descriptive results}

According to Table 1 the experimental group has a mean age of $11.33 \pm 1.03$, and the average of the results of the initial and the final test for the speed in 10 meters are respectively $(2.35 \pm 0.09),(2.25 \pm 0.06)$.

For Uchi Komi test the mean of the initial and final test results are respectively $(7 \pm 0.9),(8.7 \pm 1.03)$.

From Table 2 the control group has a mean age of $11.33 \pm 1.03$, as well as the average of the results of the initial and the final test for the speed in 10 meter are respectively $(2.61 \pm 0.25),(2.60 \pm 0.19)$.

For Uchi Komi test the average of the initial and final test results are respectively $(6.67 \pm 1.37),(7.67 \pm 1.21)$.

Results of the comparison between the experimental group and the control group.

- Speed test on $10 \mathrm{~m}$ in $(\mathrm{s})$

- For the experimental group and from Table 3, the average of the initial test was $2.35 \pm 0.09$, and the final test was $2.25 \pm 0.06$, which proves an evolution of 0.1 (s). And this is confirmed by the paired sample T-test, which shows that there is a significant difference between the value of

Table 1. General characteristics of the sample as well as the results of the initial and final tests of the two tests (speed over $10 \mathrm{~m}$ and Uchi Komi by 10 seconds (Ippon Seoi Nage)) for the experimental group.

\begin{tabular}{llllllll}
\hline Subjetcs & $\begin{array}{l}\text { Ages } \\
\text { (years) }\end{array}$ & $\begin{array}{l}\text { Weight } \\
\mathbf{( k g )}\end{array}$ & Grades & $\begin{array}{l}\text { IT*: } \\
\mathbf{1 0 m}(\mathbf{s})\end{array}$ & $\begin{array}{l}\text { FT*: } \\
\mathbf{1 0 m}(\mathbf{s})\end{array}$ & $\begin{array}{l}\text { IT : } \\
\text { Uchi } \\
\text { Komi }\end{array}$ & $\begin{array}{l}\text { FT: Uchi } \\
\text { Komi }\end{array}$ \\
\hline 1 & 12 & 43 & Blue & 2.30 & 2.18 & 8 & 10 \\
2 & 12 & 59 & Blue & 2.41 & 2.32 & 8 & 9 \\
3 & 10 & 41 & Blue & 2.47 & 2.33 & 6 & 7 \\
4 & 12 & 78 & yellow & 2.25 & 2.19 & 7 & 9 \\
5 & 12 & 58 & white & 2.29 & 2.25 & 7 & 9 \\
6 & 10 & 41 & white & 2.40 & 2.25 & 6 & 8 \\
$* * * *$ & $11.33 \pm 1.0$ & $53.3 \pm 14.65$ & $* * * *$ & $2.35 \pm 0.09$ & $2.25 \pm 0.06$ & $7 \pm 0.9$ & $8.7 \pm 1.03$ \\
\hline
\end{tabular}

Note: IT*: Initial test, $\mathrm{FT}^{*}$ : Final test.

Table 2. General characteristics of the sample as well as the results of the initial and final tests of the two tests (speed over $10 \mathrm{~m}$ and Uchi Komi by 10 seconds (Ippon Seoi Nage)) for the control group.

\begin{tabular}{|c|c|c|c|c|c|c|c|}
\hline Subjects & Ages & $\begin{array}{l}\text { weight } \\
\text { (kg) }\end{array}$ & Grades & $\mathrm{IT}^{*}: 10 \mathrm{~m}(\mathrm{~s})$ & $\begin{array}{l}\text { FT 10m } \\
\text { (s) }\end{array}$ & $\begin{array}{l}\text { IT*: Uchi } \\
\text { Komi }\end{array}$ & $\begin{array}{l}\text { FT*: Uchi }^{*} \\
\text { Komi }\end{array}$ \\
\hline 1 & 12 & 40 & Blue & 2,15 & 2,29 & 9 & 7 \\
\hline 2 & 10 & 40 & Green & 2,70 & 2,71 & 7 & 9 \\
\hline 3 & 12 & 55 & Orange & 2,85 & 2,65 & 7 & 9 \\
\hline 4 & 12 & 45 & Orange & 2,60 & 2,50 & 6 & 6 \\
\hline 5 & 12 & 48 & White & 2,81 & 2,86 & 5 & 8 \\
\hline 6 & 10 & 49 & white & 2,53 & 2,60 & 6 & 7 \\
\hline$* * * *$ & $11.33 \pm 1.03$ & $46.16 \pm 5.7$ & $* * * * *$ & $2.61 \pm 0.25$ & $2.60 \pm 0.19$ & $6.67 \pm 1.37$ & $7.67 \pm 1.21$ \\
\hline
\end{tabular}

Note: IT*: Initial test, $\mathrm{FT}^{*}$ : Final test. 
Table 3. Comparison of the initial and the final test of $10 \mathrm{~m}$ speed test between the two groups

\begin{tabular}{|c|c|c|c|c|c|}
\hline \multicolumn{3}{|c|}{ Experimental Groupe } & \multicolumn{2}{|c|}{ Control Groupe } & \multirow[b]{2}{*}{ Sig* } \\
\hline Initial test & Final test & Sig* & Initial test & Final test & \\
\hline$A^{*} \pm S d^{*}$ & $\mathrm{~A}^{*} \pm \mathrm{Sd}^{*}$ & 0.003 & $A^{*} \pm S d^{*}$ & $A^{*} \pm S d^{*}$ & 0.93 \\
\hline $2.35 \pm 0.09$ & $2.25 \pm 0.06$ & & $2.61 \pm 0.25$ & $2.60 \pm 0.19$ & \\
\hline
\end{tabular}

Note: $\mathrm{A}^{*}$ : average, $\mathrm{Sd}^{*}$ : standard deviation Sig*: signification.

Table 4. Comparison of the initial and the final test of Uchi Komi test of 10 seconds (Ippon Seoi Nage) between the two groups

\begin{tabular}{|c|c|c|c|c|c|}
\hline \multicolumn{3}{|c|}{ Experimental Groupe } & \multicolumn{3}{|c|}{ Control Groupe } \\
\hline Initial test & Final test & Sig* & Initial test & Final test & Sig* \\
\hline$A^{*} \pm S d^{*}$ & $A^{*} \pm S d^{*}$ & 0.001 & $A^{*} \pm S d^{*}$ & $A^{*} \pm S d^{*}$ & 0.23 \\
\hline $7 \pm 0.9$ & $8.7 \pm 1.03$ & & $6.67 \pm 1.37$ & $7.67 \pm 1.21$ & \\
\hline
\end{tabular}

Note: $\mathrm{A}^{*}$ : average, $\mathrm{Sd}^{*}$ : standard deviation Sig*: signification.

the initial test and the final test $(p=0.003 \leq 0.05)$.

- For the control group and from Table 3, the average of the initial test was $2.61 \pm 0.25$, and the final test was $2.60 \pm 0.19$, which proves a difference of 0.01 , but based on the paired T-samples test, we can see that there is no statistically significant difference $(\mathrm{p}=0.93 \geq 0.05)$.

- Uchi Komi test of 10 seconds (Ippon Seoi Nage)

- For the experimental group and from Table 4, the average of the initial test was $7 \pm 0.9$, and the final test was $8.7 \pm$ 1.03, which proves an evolution of about 1.7 And this is confirmed by the paired sample T test, which demonstrates that there is a significant difference between the value of the initial test and the final test $(p=0.001 \leq 0.05)$.

- For the control group and from Table 4, the average of the initial test was $6.67 \pm 1.37$, and the final test was 7.67 \pm 1.21 , which proves a difference of the order of 1 , but based on the T-test of paired samples, we find that this evolution is not statistically significant ( $p=0.23 \geq 0.05$ ), and thereafter it is not considerable.

\section{Discussion}

According to Table 1 and 2, the experimental group and the control group have the same middle age (11.33 \pm $1.03)$, and this was part of the sample choices in order to have the same starting conditions for both study groups.

According to both Tables 3 and 4, comparing the results of the initial test $(2.35 \pm 0.09)$ and final test $(2.25 \pm 0.06)$ for the test of speed of 10 meters for the experimental group, we manage to have an evolution of the order of $0.1(\mathrm{~s})$, and this is was confirmed by the T-test of paired samples, which shows that there is a significant difference between the value of the two initial and final tests $(p=0.003 \leq 0.05)$. The same result was recorded for Uchi Komi test $(\mathrm{p}=0.001 \leq 0.05)$, between the initial test $(7 \pm 0.9)$ and the final test $(8.7 \pm 1.03)$, while in the control group the results for either the $10 \mathrm{~m}$ speed test or Uchi Komi test are not significant respectively $(p=0.93 \geq 0.05)$, $(\mathrm{p}=0.23 \geq 0.05)$.
These encouraging results can only be explained by the effectiveness of the training program developed and applied during the experimental period (12 weeks), and of course by the impact of coordination on the development of physical qualities, and this was widely discussed in several scientific articles on judo and other combat sports: fencing [12-15], judo [16-18], wrestling [19, 20], kickboxing [21, 22], taekwondo [19, 21, 23], but other authors put forward very different and different opinions regarding the experimental data on the importance of particular coordination in combat sports, a researcher named Petrow in 1997 [24], claims that no scientist has further determined the structure of coordination motor skills that significantly affect performance in certain combat sports.

\section{Conclusion}

The development of physical qualities is still the primary goal of coaches; however, this development is more decisive for young athletes. Our study has shown that a coordination training that is age adapted can help coaches better develop a number of qualities namely speediness.

\section{Thanks}

To the entire staff of Svelty club, and especially to the coach Mr Safouane Attaf for the help he has given us to develop this work, and for his valuable contribution and advice throughout the realization of this job.

\section{Contributions of the authors}

All the authors contributed to the conduct of this work.

\section{Conflicts of interest}

The authors declare no conflict of interest. 


\section{References}

1. Ebine K. Physiological characteristics of exercise and findings of laboratory tests in Japanese elite judo athletes. Médicine du Sport. 1991; 65: 73-79.

2. Favre-Juvin A, Majean H, Gaillat L, Eterradossi J. Approche physiologique du judo [Physiological approach of judo]. Med Sport; 1989; 40: 5-10. (In French)

3. Monteiro LF. Structure et coût énergétique des combats de judo [Structure and energy cost of judo fights]. 2nd International Judo Federation World Judo Conference in Munich, Germany. 2001. P. 100-107. (In French)

4. Houvenaeghel M. Mesure continue de la fréquence cardiaque en entraînement spécifique de judo [Continuous measurement of heart rate in specific judo training]. Science \& sports. 2005; 20(1) :27-32. (In French) https://doi.org/10.1016/j.scispo.2004.05.009

5. Jagiello W. Differentiation of the body composition in taekwondo-ITF competitors of the men's Polish national team and direct based athletes. Archives of Budo. 2015;11:329-38.

6. Vandeberg D, Weemaels G. Ds Athletic Academy: une approche progressive pour favoriser le développement optimal des qualités [Physiques a progressive approach to foster the optimal development of physical qualities]. Science \& Sports. 2014; 29: S32. (In French) https://doi.org/10.1016/j.scispo.2014.08.066

7. Doroshenko EY, Svatyev AV, Iermakov SS, Jagiello W. The use of cardio training facilities in training 7-9-year-old judo athletes. Archives of Budo Science of Martial Arts and Extreme Sports. 2017;13:165-72.

8. Osipov AY, Kudryavtsev MD, Iermakov SS, Jagiello W, Doroshenko SA. Development of the ability to maintain body balance in young athletes 12-13 years practicing judo. Archives of Budo Science of Martial Arts and Extreme Sports, 2018;14:21-30.

9. Almansba R, Franchini E, Sterkowicz S. Uchikomi avec charge, une approche physiologique d'un nouveau test spécifique au judo [Uchi-komi with load, a physiological approach of a new specific test to judo]. Science \& Sports. 2007; 22(5): 216-223. (In French) https://doi.org/10.1016/j.scispo.2007.06.006

10.Lefevre T. Etude des effets de la fréquence cardiaque d'entrainement en vitesse [Study of the effects of speed training heart rate]. 2014. (In French)

11.Paillard T. Optimisation de la performance sportive en judo Optimization of sport performance in judo. De Boeck Supérieur; 2010. (In French)

12.Sadowski Jerzy. Dominant coordination motor abilities in combat sports. Journal of human kinetics. 2005; 13: 61.
13.Kriventsova I, Pashkevych S, Iermakov S, Bartik P, Michal J, Nosko M, et al. Fitness - aerobic training of 15 - 17 years' age girl students, who have significant risk of deviations in backbone functional state. Journal of Human Sport and Exercise. 2017;12(4):1289-1297. https://doi.org/10.14198/jhse.2017.124.15

14.Jagiello W, Jagiello M, Kalina RM, Barczynski BJ, Litwiniuk A, Klimczak J. Properties of body composition of female representatives of the Polish national fencing team - the sabre event. Biology of Sport. 2017;34(4):401-406. https://doi.org/10.5114/biolsport.2017.70526

15.Czajkowski Z. From agility to corporative abilities. Sport Wyczynowy. 1993; 18: 3-4 (in Polish)

16.Manolaki VG. Teachers monitor the level of preparedness of skilled wrestlers on stage sporting perfection. [PhD thesis]. Moscow; 1990. (In Russian)

17.Jagiello W, Wolska B, Sawczyn S, Dornowski M. The similarity of training experience and morphofunctional traits as prediction criteria of the sports level in subsequent stages of long-term women's judo training. Archives of Budo. 2014;10.

18. Todorow AS. Control coordination movements of freestyle wrestlers. [PhD thesis]. Moscow; 1991. (In Russian)

19.Lee KM. Taekwondo kyorugi: sports combat training. Centralny Ośrodek Sportu; 1998. (In Polish)

20.Romanenko V, Podrigalo L, Iermakov S, Rovnaya O, Tolstoplet E, Tropin Y, et al. Functional state of martial arts athletes during implementation process of controlled activity comparative analysis. Physical Activity Review. 2018;6:87-93. https://doi.org/10.16926/par.2018.06.12

21.Bujak Z. Differences in the level of selected elements of motor coordination among taekwon-do contestants at unsophisticated and masterly level. Movement Coordination in Team Sport Games and Martial Arts. 1998: 25-28. (In French)

22. Volodchenko OA, Podrigalo LV, Iermakov SS, Zychowska MT, Jagiello W. The Usefulness of Performing Biochemical Tests in the Saliva of Kickboxing Athletes in the Dynamic of Training. Biomed Research International, 2019:2014347. https://doi.org/10.1155/2019/2014347

23.Sadowski J. Studies of selected elements of movement coordination in taekwondo athletes. Rocz. Nauk. IWFiS. 1999; 5: 37-40.

24.Pietrow AM. Central programs are the mechanisms for implementation of coordinating sportsmen's methods and their pedagogical skills. [PhD thesis]. Moscow; 1997. (in Russian) 


\section{Information about the authors:}

Zeghari L.; (Corresponding author); https://orcid.org/0000-0001-6769-6864; zegharilotfi@gmail.com; Royal Institute of Management training, National Center of Sports Moulay Rachid, Salé; National Center of Sports Moulay Rachid, Road of Meknes Km 12, Salé, Morocco.

Moufti H.; http://orcid.org/0000-0001-6421-1454; h_moufti@yahoo.fr; Royal Institute of Management training, National Center of Sports Moulay Rachid, Salé; National Center of Sports Moulay Rachid, Road of Meknes Km 12, Salé, Morocco.

Arfaoui A.; http://orcid.org/0000-0002-5705-2536; amine_arfaoui@yahoo.fr; Royal Institute of Management training, National Center of Sports Moulay Rachid, Salé; National Center of Sports Moulay Rachid, Road of Meknes Km 12, Salé, Morocco.

Gaidi A.; https://orcid.org/0000-0002-0037-4657; gaidiabdoujudo@gmail.com; Royal Institute of Management training, National Center of Sports Moulay Rachid, Salé; National Center of Sports Moulay Rachid, Road of Meknes Km 12, Salé, Morocco.

Addal K.; https://orcid.org/0000-0001-8995-5417; khadija.addal1997@gmail.com; Royal Institute of Management training, National Center of Sports Moulay Rachid, Salé; National Center of Sports Moulay Rachid, Road of Meknes Km 12, Salé, Morocco..

Cite this article as:

Zeghari L, Moufti H, Arfaoui A, Gaidi.A, Addal K. Impact of coordination training on the development of speed among young judokas from 10 to 12 years old. Pedagogics, psychology, medical-biological problems of physical training and sports, 2019;23(6):325-329.

https://doi.org/10.15561/18189172.2019.0608

This is an Open Access article distributed under the terms of the Creative Commons Attribution License, which permits unrestricted use, distribution, and reproduction in any medium, provided the original work is properly cited (http://creativecommons.org/licenses/by/4.0/deed.en).

Received: 07.08.2019

Accepted: 25.07.2019; Published: 30.09.2019 